www.jmscr.igmpublication.org

Impact Factor 5.244

Index Copernicus Value: 83.27

ISSN (e)-2347-176x ISSN (p) 2455-0450

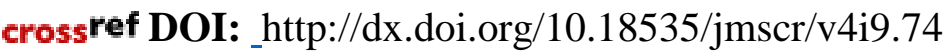

Journal Of Medical Science And Clinical Research

IGM Publication

An official Publication of IGM Publication

\title{
Epidemiological Analysis of Femoral Fractures in Kashmiri Children
}

\author{
Authors \\ Mehmood Ul Hassan Mufti ${ }^{1}$, Sheikh Ajaz ${ }^{2}$, Raja Rameez Farooqi ${ }^{3}$ \\ Muhammad Ashraf Khan ${ }^{4}$, Hilal Ah Kotwal ${ }^{5}$ \\ 1,2,3,4,5 Resident, Dept. of Orthopaedics, Govt. Medical College, Srinagar \\ *Corresponding Author \\ Mehmood Ul Hassan Mufti \\ Email:mehmood.mufti@gmail.com
}

\begin{abstract}
Background: This study looks at the epidemiology of femoral fractures in children in Kashmir region who were treated at our tertiary care institute, the hospital for Bone and Joint Surgery Srinagar for two years.

Method: In this retrospective study over a two-year period we studied 332children with femoral fractures who were treated at Bone and Joint Surgery Hospital Srinagar, Kashmir. Each case was studied with respect to age, sex, trauma side, fracture type, associated injuries and the mechanism leading to trauma.

Results: Annual incidence of elbow fractures was 166. Among all fractures analyzed during this interval of time, femoral fractures accounted for of all fractures, with forearm fractures (35.53\%) and elbow fractures $(32 \%)$. Rest of the fractures (8\%) constituted fractures of leg bone, clavicle, proximal humerus and others. Average age was 21/2 years. Most of the children were of age group 1 to 7 years. Among all femoral fractures males constituted $68 \%$ of all fractures and female children were $32 \%$ with male to female ratio of 2.16:1. Femoral shaft fractures constituted 58\% of all fractures. Most common mechanism of trauma was due to fall from height (49\%). Most of the associated injuries were fractures of the distal forearm (14\%) fractureclavicle (5\%), proximal humerus (4\%), hand (3\%) and scapula (2\%)

Keywords: Femur, Children, Fracture, Kashmir, Injury, Retrospective.
\end{abstract}

\section{Introduction}

As skeletal injuries are common in childhood and in order to plan preventive programs for safer environments to be possible, those injuries epidemiology of specific geographical areas must be known. ${ }^{1}$

Paediatric Fractures are most common consequence of falls and accidents and femoral fractures are the most frequent major fracture of long bones ${ }^{2}$.Femoral fractures constituted $1.7 \%$ of all the fractures in children under 16 years of age in a population based study ${ }^{3}$.
Extremities trauma is extremely common in the paediatric age group. If all musculoskeletal tissues are considered, they would constitute $40 \%$ of all childhood injuries. Such injuries include, bone fractures, dislocations, strains, sprains, tendon disruption, muscle tears, and joint pain from injuries such as bone bruises. ${ }^{4}$

It has been reported that fractures are a common event in childhood with considerable variations in the incidence rate from $1.2 \%$ to $5 \%$ among different studies. This variability may depend on the child's condition, age, and social and environmental factors. ${ }^{\text {? }}$ 
The majority of fractures in children involve the upper limb. Lower limb fractures are mainly caused by twisting injuries and road traffic accidents. $^{6}$

Extremities trauma in children should be treated as early as possible because they heal more rapidly than adult injuries do and Paediatric bony injuries are more often treated by closed reduction than by open reduction because of short time to union and the ease of obtaining and maintaining near-anatomic reductions, as well as the potential for remodeling. ${ }^{7}$

These fractures are more common in boys. Femoral fractures have peak age of two years in boys as well as girls. In the literature, studies focusing on the epidemiological aspect of femoral fractures in children are rare. In Kashmir Valley, there has been no study about the epidemiology of femoral fractures in children, thus the aim of our study was to determine the epidemiological profile of fractures of the femur in children of the valley at Bone and Joint Hospital Srinagar which is a tertiary care orthopaedic centre in the valley.

\section{Patients and Methods}

This work represents a retrospective study conducted for a period of 2 years from January 2014 to January 2016. From the hospital inpatient records, we collected all the children with femoral fractures who were treated within this time frame. 332 cases of children with femoral fractures were managed in the Bone and joint Hospital Srinagar, Kashmir for whom full documentation of trauma mechanism and other parameters for study were available. For each case, the following parameters were studied to know the frequency, age, sex, circumstances of occurrence, the mechanism, the anatomical lesion, and associated lesions. All those patients about whom some data pertaining to above mentioned parameters were missing, were excluded from our study. We then compared our results with literature data.

\section{Results of the study Epidemiology}

The frequency: In a period of 2 years we identified 332 cases of femoral fractures with an annual incidence of 166. During this time period, 17450 fractures in children were recorded. Fractures of femoral constitute around $2 \%$ of the cases, fractures of the distal forearm $(35.53 \%$ of cases) were most common as shown in Table 1.

The Age: The average age of children was $2^{1 / 2}$ years, ranging from 1 week to 14 years. A peak incidence was noted in the age group 2-3 years (Figure 1).

The Sex: Male predominance was noted with 227 cases compared to 105 cases of female children with a sex ratio of 2.16: 1 as shown in figure 1

The Causes: The causes of the femoral fracture are mostly due to fall from height with $49.4 \%$ of cases. This is followed by road traffic accidents with $28 \%$ of cases and others with rest of cases as shown in Table 2.

The anatomical lesions: The femoral shaft fractures were most common (59\% of cases) followed by fractures of the distal femur (32\% of cases) and fractures of peri-trochantaric region including the neck ( $6 \%$ of cases). Rest of the $3 \%$ includes avulsion fractures of trochanter and medial $r$ lateral epicondyle of femur fractures as shown in Table 3.

Associated Injuries: Associated injuries accounted for $5 \%$ of cases. The soft tissue lesions noted by large ecchymosis and puckering were noted in $3.4 \%$ of cases. The femoral fracture was associated with other bone lesions in $15 \%$ of cases. It was associated in 24 cases with fracture of the upper extremity and the clavicle. Of all the fractures, nearly $3 \%$ were compound. 


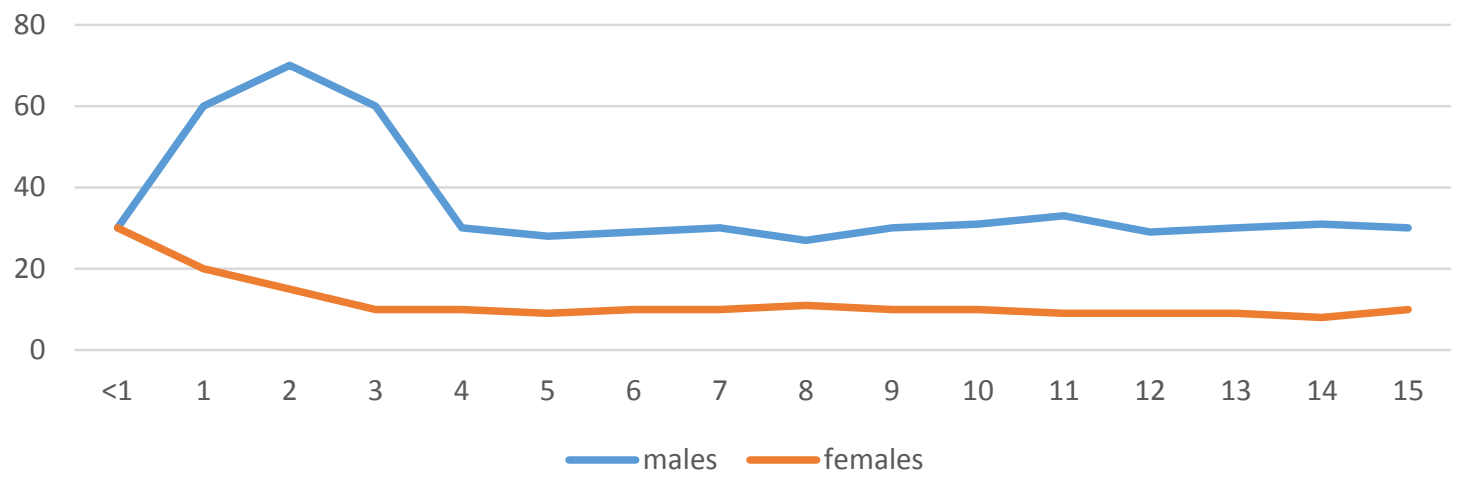

Horizontal: age

Vertical: number of patients

Table 1: Distribution of fractures recorded during the study period.

\begin{tabular}{|l|c|}
\hline Distributon of fractures & Percentage \\
\hline Forearms and wrist & $35.53 \%$ \\
\hline Elbow region & $32.65 \%$ \\
\hline Hands & $12.71 \%$ \\
\hline feet & 8.1 \\
\hline Legs and ankles & $5.7 \%$ \\
\hline Femur & $2.7 \%$ \\
\hline Others & $7.31 \%$ \\
\hline Total & $100 \%$ \\
\hline
\end{tabular}

Table 2: Distribution of patients according to the cause

\begin{tabular}{|l|c|c|}
\hline Cause of injury & No. of cases & Percentage \\
\hline Fall from height & 164 & $49.4 \%$ \\
\hline Road traffic accident & 93 & $28 \%$ \\
\hline Direct blow & 36 & $10.84 \%$ \\
\hline Animal attack & 10 & $3 \%$ \\
\hline Child abuse & 3 & $1 \%$ \\
\hline Others & 26 & $7.8 \%$ \\
\hline Total & 332 & $100 \%$ \\
\hline
\end{tabular}

Table 5: Distribution of patients according to anatomical lesion.

\begin{tabular}{|l|l|l|}
\hline $\begin{array}{l}\text { Anatomical site of } \\
\text { injury }\end{array}$ & $\begin{array}{l}\text { No. of } \\
\text { cases }\end{array}$ & Percentage \\
\hline Femoral shaft & 196 & $59 \%$ \\
\hline Distal femur & 106 & $32 \%$ \\
\hline Peri trochanteric region & 20 & $6 \%$ \\
\hline others & 10 & $2 \%$ \\
\hline Total & 332 & $100 \%$ \\
\hline
\end{tabular}

Boys constituted $68 \%$ of all patients. We did not report in our study of any nerveor vascular injury.

\section{Discussion}

Most studies on femoral fractures in children consider treatment and involue relatively small number of cases. Epidemiological studies are rare, Hinton et $\mathrm{al}^{8}$ in Maryland USA studied 1485 children with such fractures. Hedlund and Lundgren $^{9}$ studied 851 children aged with fractures of shaft of femur.

Elbaih $\mathrm{AH}^{10}$ found femoral fractures constituting $0.37 \%$ of all fractures in their study.

In contrast to other types of fractures in children in which the incidence increases with age to peak in early teens ${ }^{11}$ in femoral fractures the peak incidence was in young children (fig 1).The incidence of fractures in two-year-old boys was $50 \%$ more than in the next highest age group. In most studies single-year age bands are not described. A peak incidence in two-year-old boys was observed in Maryland, USA, ${ }^{12}$ and in Aarhus, Denmark. ${ }^{13}$ In Stock-holm, where two-year age bands were used, the highest incidence in both sexes was in two- to three-year-old children. ${ }^{12}$

The high rate of fractures in two-year-old boys requires further explanation, but may relate to the increased activity of children of this age, combined with a lack of awareness of dangers.

No gender difference in the incidence of fractures was observed for the first year of life, but then the greater risk for boys varied between 1.6 times the risk for girls at 11 years, to 4.7 times at 14 years (Fig. 1). Studies in Maryland, USA, Finland and 
Sweden have all reported two or three times more fractures in boys than in girls. ${ }^{9,13,14}$

This reflectsthe excess risk for boys for fracture for all sites. ${ }^{15}$ There has been much speculation as to why boys have a higher risk of fractures, but no convincing evidence for the reason has been reportedincreased activity of children of this age, combined with a lack of awareness of dangers.

Up to the age of four falls were the predominant cause of fractures, and thereafter traffic accidents. This is consistent with observations from Denmark, Sweden and the USA. ${ }^{19,17}$ Maltreatment was rarely ascribed as a cause, although in children under one year of age it was ascribed in $8.5 \%$ of fractures. This is in contrast to some other studies. In 74 children aged five years or younger in Oklahoma, $50 \%$ of fractures were considered by their Child Protection Committee to have been caused by child abuse, ${ }^{18}$ and in $30 \%$ of 80 cases in children under four years of age in Port-land, Oregon were considered to be caused by child abuse. ${ }^{19}$ Therefore, in circumstances in which there are conflicting accounts of the exact nature of the event that caused the injury, for example was the child pushed or did he or she slip, the results should be regarded with caution. In our study, this is pertinent to maltreatment, human action, being struck and a fall. Further research is needed.

\section{Conclusion}

We conclude that this is the largest reported study of the epidemiology of femoral fractures in children in Kashmir valley that we are aware of. The descriptive epidemiology will provide useful information for those planning interventional studies of the treatment or prevention of femoral fractures in children, or those planning services. Further research is warranted in several areas, for example the high rate in two-year-old boys, the higher rate in boys than in girls and the cases of child abuse.

\section{References}

1. Mayranapaa M, Makitie OU, Kallio PE. Fractures in children, epidemiology and associated bone health characteristics. 2012;33-8.

2. Department of Health. Compendium of clinical and health indicators 2001. London: National Centre for Health Outcomes Development, 2001.

3. Baker SP, O’Neill B, Ginsberg MJ, Li G. The injury factbook, Second ed. New York: Oxford University Press, 1992.

4. Ogden JA. Skeletal injury in the child. 1999;2:38- 69.

5. Rennie L, Court-Brown CM, Mok JY, Beattie TF. The epidemiology of fractures in children. Injury 2007;38:913-22.

6. Donaldson LJ, Reckless IP, Mindell JS, Shelton NJ. The epidemiology of fractures in England. J epidemiol community health. 2008;62:174-80.

7. Harley BJ, Beaupre LA, Jones CA, Dulai SK, Weber DW. The effect of time to definitive treatment on the rate of nonunion and infection in open fractures. $\mathbf{J}$ Orthopaedic Trauma. 2002;16(7):484-90.

8. Hinton RY, Lincoln A, Crockett MM, Sponseller P, Smith G. Fractures of the femoral shaft in children: incidence, mechanisms and sociodemographic risk factors. J Bone Joint Surg [Am] 1999;81A:500-9

9. Hedlund R, Lundgren U. The incidence of femoral shaft fractures in children and adolescents. J PediatOrthop1986;6:47-50.

10. Elbaih AH, Taha M, Saker A, Aziz S, Shahate A. Patterns of extremities trauma in children and their management in emergency department in Suez Canal University Hospital, Ismailia, Egypt. IntSurg J 2016;3:887-92

11. Landin LA. Epidemiology of children's fractures. J PediatrOrthop1997;6:79-83.

12. Hinton RY, Lincoln A, Crockett MM, Sponseller P, Smith G. Fractures of the femoral shaft in children: incidence, mech- 
anisms and sociodemographic risk factors. J Bone Joint Surg [Am] 1999;81-A:500-9.

13. Nafei A, Teichert G, Mikkelsen SS, Hvid I. Femoral shaft fractures in children: an epidemiological study in a Danish Urban Population, 1977-86. J Pediatr Orthop 1992; 12:499-502.

14. Miettinen H, Makela EA, Vainio J. The incidence and causative factors responsible for femoral shaft fractures in children. Ann ChirGynaecol1991;80:392-5.

15. Landin LA. Epidemiology of children's fractures. J PediatrOrthop1997;6:79-83.

16. Campbell SE, Campbell MK, Grimshaw JM, Walker AE. A systematic review of discharge coding accuracy. J Public Health Med 2001;23:205-11.

17. Gregory J, Lowe S. National diet and nutrition survey: young people aged 4 to 18 years. Vol 1 Report of the diet and nutrition survey. London: Stationery Office, 2000.

18. Gross RH, Stranger M. Causative factors responsible for femoral fractures in infants and young children. J Paediat Orthop 1983;3:341-3.

19. Beals RK, Tufts E. Fracture femur in infancy: the role of child abuse. J PediatrOrthop1983;3:583-6. 